\title{
Production of sexuals in a fission-performing ant: dual effects of queen pheromones and colony size
}

\author{
Raphaël Boulay \& Abraham Hefetz \& Xim Cerdá \& \\ Séverine Devers \& Wittko Francke \& Robert Twele \& \\ Alain Lenoir
}

\begin{abstract}
Models based on the kin selection theory predict that in social hymenopterans, queens may favor a lower investment in the production of sexuals than workers. However, in perennial colonies, this conflict may be tuned down by colony-level selection because of the trade off between colony survival and reproductive allocation. In this study, we present a survey of sexual production in colonies of Aphaenogaster senilis, a common species of ant in the Iberian Peninsula. Similar to most species that reproduce by fission, males were found in large excess compared to gynes (172:1). Sexuals were more likely to be found in queenless than in queenright (QR) field colonies. However, we also found a few gynes and numerous males in very
\end{abstract}

\footnotetext{
Communicated by J. Heinze

R. Boulay $(\star) \cdot X$. Cerdá

Estación Biológica de Doñana, Consejo Superior de

Investigaciones Científicas,

Avenida María Luisa s/n,

41013 Sevilla, Spain

e-mail: boulay@ebd.csic.es

\section{A. Hefetz}

Department of Zoology, George S. Wise Faculty of Life Sciences, Tel Aviv University,

Ramat Aviv,

69978 Tel Aviv, Israel

\section{S. Devers A. Lenoir}

Institut de Recherches sur la Biologie de l'Insecte, CNRS UMR

6035, Faculté des Sciences, Université François Rabelais,

Parc de Grandmont,

37200 Tours, France

W. Francke ${ }^{\circ}$ R. Twele

Institut für Organische Chemie, Universität Hamburg,

Martin Luther King Platz 6,

20146 Hamburg, Germany
}

large QR colonies. We compared these data with those available in the literature for $\mathrm{A}$. rudis, a congeneric species from North America that has independent colony founding. The sex ratio in this species was only five males for each female, and sexuals were mostly found in QR nests, irrespective of colony size. We confirmed queen inhibition of sexual production in A. senilis in laboratory experiments and provide evidence that this inhibition is mediated by a nonvolatile pheromone. To seek the potential source of such a queen pheromone, we analyzed the secretions of two conspicuous exocrine glands, the Dufour's and postpharyngeal glands (DG and PPG, respectively) in both queens and workers. Both secretions were composed of hydrocarbons, but that of DG also contained small quantities of tetradecanal and hexadecanal. The hydrocarbon profile of the DG and PPG showed notable caste specificity suggesting a role in caste-related behavior. The PPG secretions also differed between colonies suggesting its role in colonylevel recognition. We suggest that in A. senilis, there are two modes of colony fission: First, in very large colonies, gynes are produced, probably because of the dilution of the queen pheromone, and consequently one or more gynes leave the mother colony with workers and brood to found a new nest. This is beneficial at the colony level because it avoids the production of costly sexuals in small colonies. However, because the queen and workers have different optima for sexual production, we hypothesize that queens tend to overproduce the pheromone to delay their production. This in turn may drive workers to leave the mother colony during nest relocation and to produce sexuals once they are away from the queen's influence, creating a second mode of colony fission.

Keywords Sexual production · Queen pheromones · Colony fission $\cdot$ Reproductive conflict 


\section{Introduction}

Although colonies of social insects are characterized by a high level of cooperation between individuals, there are also multiple entangled conflicts of interests (Mehdiabadi et al. 2003). One such conflict is between workers and queens over the proportion of resources allocated into sexuals vs workers (reproductive allocation). Models based on the kin selection theory have suggested that workers are selected to capitalize on a relatively high investment in sexuals, while the queen may gain more by investing more in workers, which guarantee better colony survival (Pamilo 1991). However, the reproductive allocation conflict is also deeply affected by the colony social structure. It may be limited in species in which the workers' inclusive fitness relies exclusively on the queen offspring, or it may be extended if workers have an opportunity to replace the actual queen with a more fertile or more related one (Bourke and Chan 1999; Bourke and Ratnieks 1999; Herbers et al. 2001). In species that form perennial nests, the expression of caste conflict over reproductive allocation may be constrained by colony-level selection. Like solitary iteroparous organisms, colonies cannot allocate an excessively high proportion of resources to reproduction because this would jeopardize their survival. This explains why small nests generally allocate a lower proportion of resources than larger ones to reproduction (Oster and Wilson 1978; Brian 1979; Elmes and Wardlaw 1982). This is also in agreement with the observation that augmentation of sexual production parallels colony productivity (Sundström 1995) and resource availability (Herbers and Banschbach 1998; Aron et al. 2001), although other studies have failed to find such a relation (Backus 1995; Herbers and Banschbach 1999; Walin and Seppä 2001). The effect of colony size and resource availability may be further confounded because large colonies are also likely to dominate resources and to collect relatively higher quantities of food than smaller ones.

A particular aspect of reproductive allocation conflicts concerns the proportion of resources invested into gynes vs workers (caste allocation conflict). Studies conducted on various social hymenopterans have demonstrated that queens limit or determine the timing of gyne production. In the honeybee Apis mellifera, gyne (virgin queens) production in the presence of the queen is limited to the swarming period, but if the queen is removed, emergency queen cells are immediately constructed and several gynes are reared (Butler 1961; Winston et al. 1990). In the bumble bee Bombus terrestris, the timing of gyne production seems to be under queen influence (Alaux et al. 2005, 2006). Similar queen influence was also demonstrated in several ant species including Solenopsis invicta (Vargo 1988), Linepithema humile (Vargo and Passera 1991, 1992), Cataglyphis iberica (Cerdá et al. 2002), and Monomorium pharaonis (Lim and
Lee 2005). The queen may directly affect larval physiology, or she may inhibit gyne production indirectly by modifying worker behavior. Hence, apart from a few notable cases of maternal effect (de Menten et al. 2005) or genetic control (Julian et al. 2002; Volny and Gordon 2002), the differentiation between gynes and workers seems to occur at the larval stage and depend on the type of care provided by the nurses (Wilson 1971; Brian 1973; Vargo and Passera 1991; Wheeler 1994). In addition, while workers of many species have retained functional ovaries and could increase the colony reproductive allocation by laying their own male eggs, other constraints (worker-worker conflicts over male parentage and colony-level selection) generally prevent them from doing so under queenright (QR) conditions (Woyciechowski and Łomnicki 1987; Ratnieks 1988; Hammond and Keller 2004). Under queenless (QL) conditions, these constraints disappear, and workers produce male offspring.

The queen's presence is generally conveyed through pheromonal bouquets that she emits and that can be spread via the workers throughout the nest. These pheromones may act coercively to manipulate workers, or they may act as a signal that informs workers and directs them to behave so as to gain maximum fitness (queen vs worker control; Keller and Nonacs 1993). In the honeybee, the queen mandibular secretion affects both worker ovarian development (Butler 1959; Hoover et al. 2003) and the construction of royal cells in which gynes are reared (Winston et al. 1990; Pettis et al. 1995; Dor et al. 2005). However, in this species, the inhibitory effect of the queen mandibular secretions alone is not as efficient as the actual presence of a fertile queen suggesting that other glands are involved (Katzav-Gozansky et al. 2006). In particular, the Dufour gland (DG hereafter) secretions that inhibit the production of queen-like secretions in workers may also participate in the complex queen pheromonal bouquet (Katzav-Gozansky et al. 2004). In the red imported fire ant S. invicta, the queen's poison gland is a source of multiple pheromones (Vander Meer et al. 1980; Vargo 1997) that may be complemented by the secretions of the postpharyngeal gland (PPG hereafter; Vargo and Hulsey 2000). It is worth mentioning that the PPG in many ant species has the same hydrocarbon composition as the epicuticle, which may be the path via which these putative pheromones are externalized. Many studies indicate that cuticular hydrocarbons act as fertility signals that govern individual workers' reproductive decisions (Peeters et al. 1999; Liebig et al. 2000; CuvillierHot et al. 2001, 2004; Heinze et al. 2002; Monnin et al. 2002; Dietemann et al. 2003). In a recent study on Camponotus floridanus, it was found that the queen marks her eggs with her own hydrocarbons and uses them as a vehicle to signal her presence in the giant nest (Endler et al. 2004). However, a large body of evidence also suggests that cuticular hydrocarbons serve as colony recognition cues 
(Vander Meer and Morel 1998; Lahav et al. 1999; Lenoir et al. 1999; Thomas et al. 1999; Wagner et al. 2000). Whether both functions are compatible, however, has remained elusive because colony and caste specificities in hydrocarbon composition have rarely been analyzed together in the same study.

The present study investigates the reproductive strategy of the ant Aphaenogaster senilis, a species that reproduces by colony fission whereby workers participate in colony foundation. A consequence of fission is that the number of female propagules is limited by the size of the mother colony and the minimum number of workers necessary to initiate a new nest. Moreover, colony fission may provoke local resource competition compared to independent colony founding, especially in ants, because dispersal of female propagules is limited by the lack of wings in workers. Consequently, the payoff of producing many gynes may be reduced compared to the production of males, which disperse farther away from the mother colony (Craig 1980; Bulmer 1983; Bourke and Franks 1995; Pearcy and Aron 2006).

Our aim was to test some of the pertinent predictions of the reproductive allocation theory in light of the peculiar mode of colony fission of A. senilis. According to pioneering works, fission occurs after a nest relocation, when part of the worker force abandons the old colony and founds a new one by producing a new queen (Ledoux 1971, 1976a). This differs from other well-known species like the army ants or the honeybee in which new queens are produced before the fission event (Gotwald 1995; Seeley 1995). We analyzed the number of males and gynes produced in fieldcollected QR and QL colonies. If only the queen affects reproductive allocation, we expected to find more males and gynes in QL colonies. If colony-level selection also acts on reproductive allocation, we expected sexual production to covary with colony size. We compared our data with those available in the literature for Aphenogaster rudis (Headley 1949; Talbot 1951), a species that performs independent colony foundation (Heithaus and Lubertazzi, personal communication). Worker ovarian development was also assessed for A. senilis under natural QL and QR conditions. Finally, we tested the volatility of the A. senilis queen signal in the laboratory and analyzed caste specificity of the PPG and DG, as a prerequisite to their potential implication in queen inhibition of sexual production.

\section{Materials and methods}

Sexual production, colony size, social condition, and worker ovarian development in nature

Demographic data were obtained from 151 nests of A. senilis collected between December 2002 and August 2006 near the Doñana National Park (South Spain: $36^{\circ} 58^{\prime} \mathrm{N}$, $6^{\circ} 28^{\prime} \mathrm{E}$ ) and 17 nests collected in Cataluña (North East

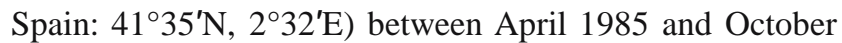
1988 (total, 168 nests). Both regions are characterized by a typical Mediterranean climate with a long warm and dry season and a cool winter. Moreover, preliminary analyses indicate that both populations have enough behavioral (diets and foraging activity) and demographic (nest density) similarities to pool the data (Cerdá and Boulay, personal observations). A few hours after nest collection, adult workers and sexual adults and pupae of both sexes were counted in all nests. 248 and 232 workers from three QL and four QR field-collected colonies of A. senilis, respectively, were also dissected to assess their ovarian development. We discriminated between two levels of ovarian development: 0 , no oocyte in formation and 1 , at least one oocyte in formation in one ovariole.

Sexual production in A. senilis was compared with two data sets available for A. rudis that present the demography of 117 nests collected from two populations in Ohio and Missouri between 1944 and 1949 (Headley 1949; Talbot 1951).

Queen signal volatility and effect on sexual production

The effect of A. senilis queens on the production of sexuals was studied in the laboratory using 20 freshly collected medium-sized colonies. Each was maintained in a plastic box that was divided into three $10 \times 7 \times 5$-cm-adjoining compartments each housing equal-sized colony fragments (between 300 and 400 workers and about 100 young larvae). Workers of the fragment situated in the middle remained QR (QR treatment); those of the second fragment (to the left of the QR compartment) were kept as QL but could exchange antennal contacts with their QR nestmates through a single mesh (QL-SM treatment). The third fragment (to the right of the $\mathrm{QR}$ compartment) was separated from the QR compartment through a double mesh, which allowed the passage of volatile compounds only (QL-DM treatment). A fourth fragment of equal size was maintained in a separate container completely isolated from the queen influence (QL treatment). All the fragments were fed twice a week with sliced mealworms. They were maintained in the same rearing room and submitted to the same variations of temperature $\left(22-27^{\circ} \mathrm{C}\right)$ and photoperiod (10:14 light/dark). The fragments were inspected twice a week for 14 weeks for the presence of sexuals. The newly emerged males and gynes were left in their natal fragment but were marked with a dot of paint on the thorax to ensure that they were counted only once.

Queen-worker chemical polymorphism

For chemical analyses, DG and PPG were excised from workers and queens of freshly collected colonies. Less than 
$14 \mathrm{~h}$ after collection, the ants were gently placed in Petri dishes at $9^{\circ} \mathrm{C}$ for half an hour to calm down before being frozen at $-18^{\circ} \mathrm{C}$ for about an hour. The glands were dissected under a stereomicroscope and immersed in $50 \mu \mathrm{l}$ of hexane. For workers, glands from three individuals were pooled per sample to obtain enough material for proper analysis. Queen secretions were copious enough to allow individual analyses. The samples were stored at $-18^{\circ} \mathrm{C}$ until analysis. Glandular content was identified by combined gas chromatography/mass spectrometry using a DB-5 fused silica capillary column that was temperature programmed from 150 to $300^{\circ} \mathrm{C}$ at $5^{\circ} \mathrm{C} \mathrm{min}^{-1}$ for PPG and from 60 to $210^{\circ} \mathrm{C}$ at $5^{\circ} \mathrm{C} \min ^{-1}$ then $15^{\circ} \mathrm{C} \min ^{-1}$ to $300^{\circ} \mathrm{C}$ for DG. Quantification was achieved by gas chromatography using the above chromatographic conditions.

\section{Statistics}

Statistical analyses were performed using SAS 9.1 (for generalized linear models [GLZs]) or Statistica 6.0 (for all other statistics). The proportions of QL and QR colonies and the proportions of single and multiple queen colonies among the QR colonies were compared between A. senilis and $\mathrm{A}$. rudis using the Pearson Chi-square test. We also checked the homogeneity of the male-to-gyne numerical ratio between Doñana and Cataluña by means of the Yatecorrected Chi-square (the total number of gynes was too small to be compared between years). A factorial analysis of variance (ANOVA) was conducted to test the effect of the social condition (QL vs QR) and species (A. senilis vs A. rudis) on colony size. The proportion of nests producing at least one gyne was determined using a GLZ with the binomial error distribution and the Logit link function. For A. senilis, the predictors were "social condition" and "colony size" nested within "social condition." This permitted testing the effect of colony size independently for QL and QR colonies. In A. rudis, no gyne was found in QL nests (see "Results"); therefore, the GLZ for this species could only test the colony-size effect. The effects of social condition and colony size nested within social condition were also tested on the numbers of males per colony using the Poisson error distribution and Log link function. Main effects were tested with type 3 likelihood ratio (LR) test. The Wald Chi-square test was used to test whether the colony size was positively or negatively associated with gyne and male production in QL and QR colonies. Finally, the percentage of workers with level 1 ovarian development was compared between QL and QR colonies with a mixed model, with the binomial error distribution and Logit link function in which the colony was treated as a random factor. Models-adjusted means and standard errors were calculated from the parameter estimates (Littell et al. 1996).
The results of the laboratory experiments were analyzed with nonparametric statistics. The absolute numbers of gynes and males were compared between treatments $(\mathrm{QR}$, QL-SM, QL-DM, and QL) with the Friedman ANOVA by ranks. Pairwise differences were estimated using a Statistica Visual Basic macro available at http://www.statsoft.nl/, which consists of a post-hoc test based on the differences of sums of ranks (DSR hereafter; Zar 1984).

Analysis of the hydrocarbon profiles was performed using peaks that were identified in all the samples and whose averages across all the samples (including workers and queens) were higher than $1 \%$. To eliminate colinearity and reduce the impact of high percentages, chemical variables were standardized as follows:

$y_{i, j}{ }^{1 / 4} \frac{y_{i ; j}-b_{i}}{s_{i}}$

where $y_{i, j}$ is the percentage value for peak $i$ in the sample $j$, and $\wp_{i}$ and $\sigma_{i}$ are the mean percentage and standard deviation of peak $i$ in all samples. $Y_{i, j}$ ' varied between -1 and +1 and had a mean of 0 (Quinn and Keough 2002). Differences in profiles were first explored using the principal components analysis (PCA). Eigenvectors (ev hereafter) were used to estimate the contribution of the chemical variables to each axis. Multiple ANOVAs were then conducted on the scores of five main components extracted from the PCA to estimate profile differences between castes and colonies. Main effects "caste" and "colony" were tested using Pillai's trace. ANOVA gave differences between castes and colonies for each component independently.

\section{Results}

Sexual production, colony size, social condition and worker ovarian development in nature

Of the 168 excavated nests of A. senilis, 154 (91.7\%) were QR and 14 (8.3\%) were QL. These proportions did not differ significantly from those of A. rudis in which 108 nests (92.3\%) were QR and nine nests (7.7\%) were QL (Pearson Chi-square, $X_{1}^{2} 1 / 4$ 0:04; P $\left.1 / 40: 845\right)$. However, among the QR nests, the proportion of multiple-queen colonies was higher in A. rudis (17.6\%) than in A. senilis (less than 1\%; Pearson Chi-square, $\left.X_{2}^{2} 1 / 425: 84 ; \quad P<0: 001\right)$. Field-collected colonies of A. senilis contained an average of $1,260 \pm 69$ workers (mean \pm SE; $n=168$; range, 121-3,906), whereas those of A. rudis were significantly smaller and contained only $301 \pm 26$ workers (mean $\pm S E ; n=117$; range, $11-2,079$; ANOVA $\left._{\text {Species, }} F_{1,264}=78.61, P<0.01\right)$. In both species, the number of workers did not differ significantly between the 
$\mathrm{QL}$ and the $\mathrm{QR}$ nests $\left(\mathrm{ANOVA}_{\text {Social condition, }} \mathrm{F}_{1,264}=0.05\right.$, $\mathrm{P}=0.829 ; \quad \mathrm{ANOVA}_{\text {Social }}$ condition $\times$ Species, $\mathrm{F}_{1}, \quad{ }_{264}=0.02$, $\mathrm{P}=0.890)$.

The pattern of sexual production in the field-collected colonies showed large differences between species. Overall, colonies of $\mathrm{A}$. rudis produced 5.5 males for each gyne while those of A. senilis produced 172.0 males for each gyne. The proportion of male to gyne in A. senilis did not differ between Cataluña and Doñana (Yate Chi-square, $X_{1}^{2} 1 / 4$ 1:40; P 1/4 0:238). In A. senilis, gyne number never exceeded three individuals per colony, and they were more likely to be produced in QL than in QR nests (Fig. 1a; LR

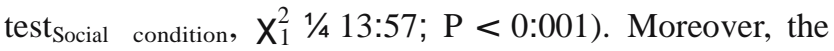
probability of gyne presence depended on colony size in

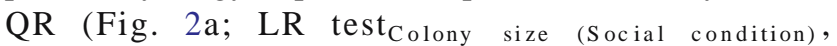
$\mathrm{X}_{1}^{2} 1 / 4$ 14:37; $\mathrm{P}<0$ 0:001; Wald Chi-square ${ }_{\text {Colont size/QR, }}$ $\mathrm{X}_{1}^{2} 1 / 49: 19 ; \mathrm{P}<0: 01$ ) but not in $\mathrm{QL}$ nests (Wald Chisquare $_{\text {Colony size/QL }}, \quad X_{1}^{2} 1 / 41: 06 ;$ P $\left.1 / 40: 303\right)$. The logistic regression indicated that the probability of gyne presence in a QR colony increases more rapidly as a function of colony size for colonies larger than half the range (e.g., larger than 1,892 workers), which represented only $12.5 \%$ of the colonies. In A. rudis, up to 33 gynes were found per colony, all of which were in QR nests (Fig. 1b) and independently of colony size (LR test $_{\text {Colony size, }} X_{2}^{2} 1 / 4$ 1:50; P 1/4 0:473).

The social condition and colony size also affected male production differently according to the species. In A. senilis, more males were produced in $\mathrm{QL}$ than in $\mathrm{QR}$ colonies

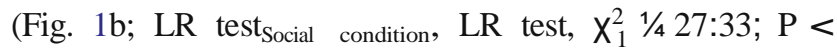
0:001). Moreover, the significant interaction between social condition and colony size (LR test Colony size (Social condition), $\mathrm{X}_{2}^{2}$ 1/4 94:03; $\mathrm{P}<0$ 0:01) revealed that the number of males increased significantly with colony size in QR (Fig. 2b; Wald Chi-square $_{\text {Colony size/QR, }} \mathrm{X}_{1}^{2} 1 / 4124: 26 ; \mathrm{P}<0$ :001) but not QL colonies (Wald Chi-square ${ }_{\text {Colony size / }}$ QL, $X_{1}^{2}{ }_{1}^{1 / 4}<$ 0:001; P 1/4 0:951). Again, the number of males per $Q R$ colony increased rapidly as a function of the number of workers only for extremely large nests. By contrast, in A. rudis, neither social condition nor colony size nested in social condition significantly affected the number of males per colony (Fig. 1d; LR tests, $X_{1}^{2} 1 / 42: 39 ; \quad$ P 1/4 0:303 and $\mathrm{X}_{1}^{2} 1 / 4$ 0:60; P 1/4 0:439, respectively).

The number of workers with developed ovaries was evenly high under QL and QR conditions (77.02 and 78.45\%, respectively; $\left.\mathrm{F}_{1,472}=2.32, \mathrm{P}=0.1284\right)$. This percentage did not vary between colonies $(\mathrm{Z}=1.42, \mathrm{P}=0.0774)$.
Fig. 1 Proportion of Aphaenogaster senilis and A. rudis nests that had at least one gyne $(a, b)$ and number of males per colony (c, d; model-adjusted means \pm SE) in field-collected nests as a function of social condition. Data for A. senilis were obtained from two populations in the Iberian Peninsula. Estimates for A. rudis were recalculated from raw data available in Headley (1949) and Talbot (1951). Double asterisks, $\mathrm{P}<0.01$; triple asterisks, $\mathrm{P}<$ 0.001 ; ns, $\mathrm{P}>0.05$; ne, nonestimable difference. Values between parentheses denote sample size

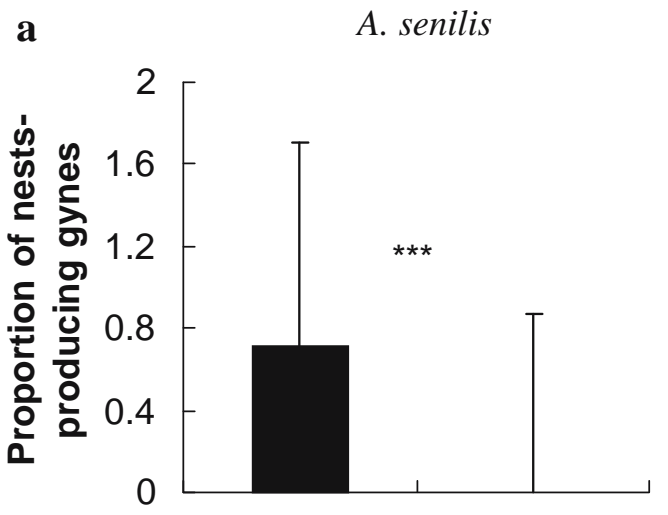

b

A. rudis

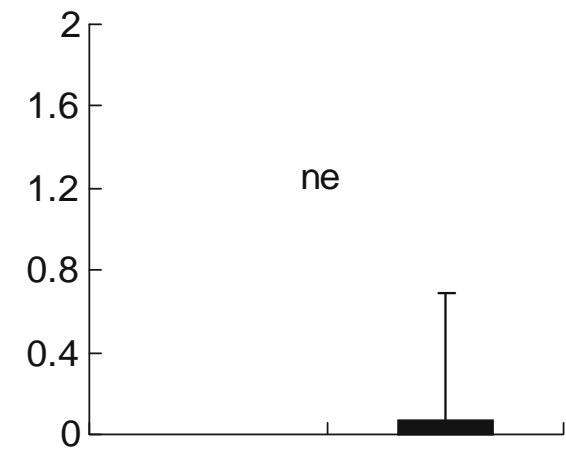

C

d

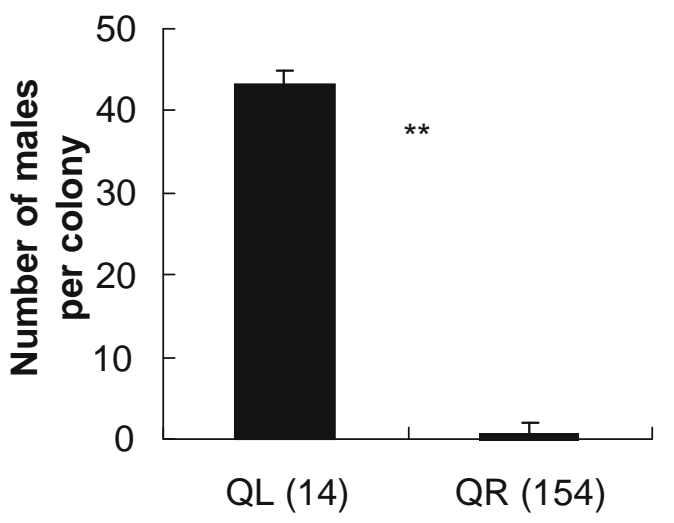

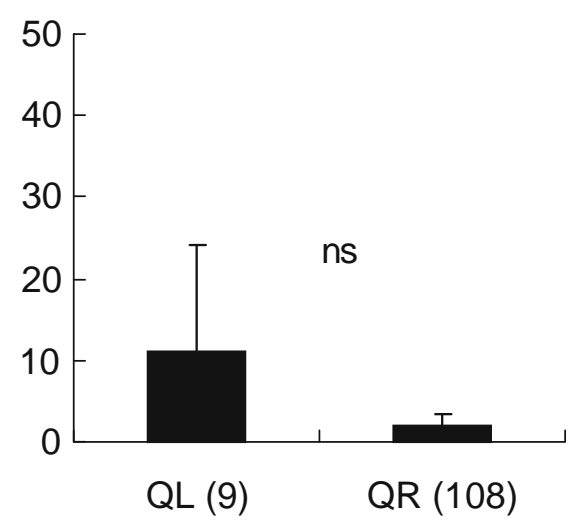

Social condition 

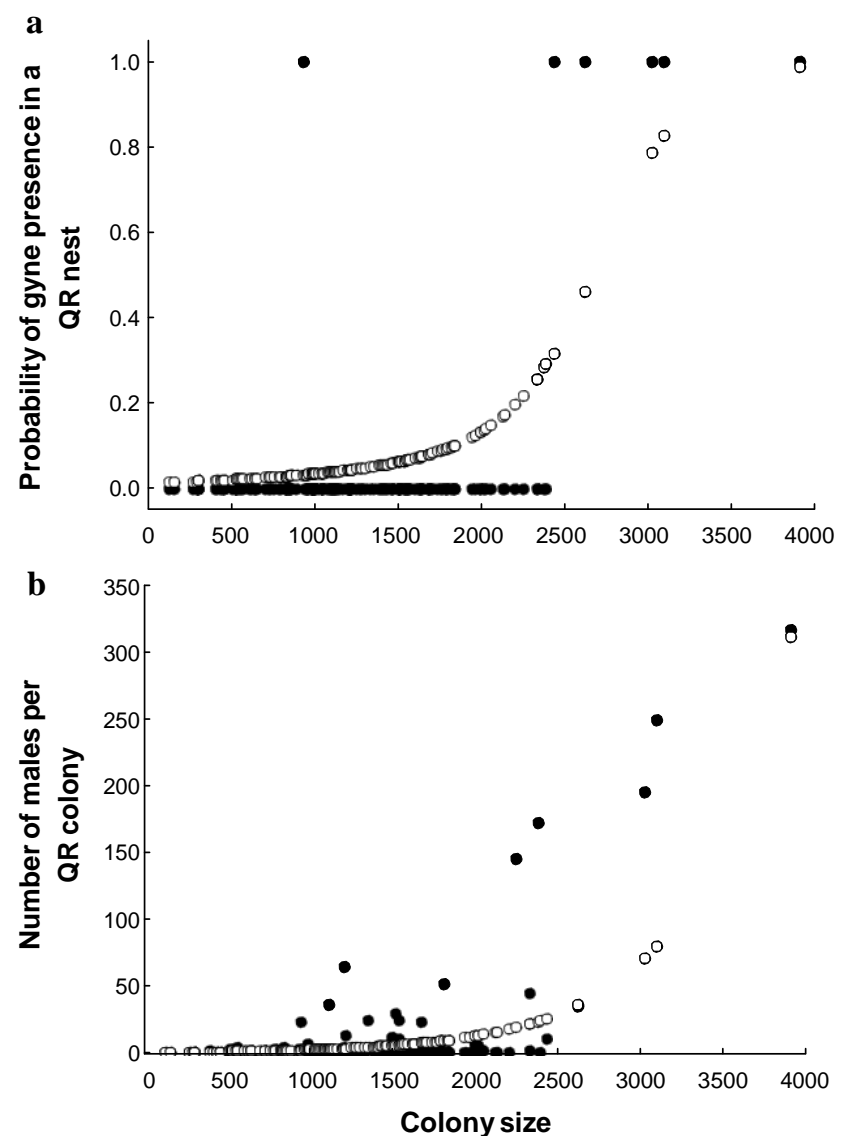

Fig. 2 Relation between colony size (number of workers) and gyne (a) and male (b) production in QR colonies of A. senilis. Black symbols are the observed data and open symbols are predicted data from the logistic and Poisson regressions, respectively

\section{Queen signal effect on sexual production}

In the laboratory, sexuals were produced from the fifth week on after the fragments separation. In total, 13 out of the 20 QL fragments, 12 out of the 20 QL-DM fragments, and 8 out of the 20 QL-SM fragments, but none of the QR fragments, produced gynes. The number of gynes produced per fragment was also clearly affected by queen presence (Fig. 3a; Friedman ANOVA, $X_{3}^{2} 1 \frac{1}{4} 24: 12 ; \mathrm{P}<0$ :001). The number of gynes produced in QL and QL-DM fragments was significantly higher than in the QR fragments (DSR= 30.5 and 22.0, respectively, $\mathrm{P}<0.05$ ), whereas the number of gynes in QL-SM fragments was intermediate and not significantly different from the QR, the QL-DM, or the QL fragments $(\mathrm{DSR}=11.5,10.5$, and 19 , respectively, $\mathrm{P}>0.05$ ). The number of males produced per fragment also differed among treatments (Fig. 3b; Friedman ANOVA, $X_{3}^{2} 1 / 4$ 17:39; $\mathrm{P}<0: 001$ ). More males were produced in the $\mathrm{QL}$ or QL-DM than in QR fragments (DSR $=25, \mathrm{P}<0.05$ and $\mathrm{DSR}=26.5, \mathrm{P}<0.01$, respectively). The number of males in the QL-SM fragments was intermediate and did not significantly differ from the $\mathrm{QR}(\mathrm{DSR}=16.5, \mathrm{P}>0.05)$, the
QL-DM $(\mathrm{DSR}=10, \mathrm{P}>0.05)$, or the $\mathrm{QL}(\mathrm{DSR}=8.5, \mathrm{P}>0.05)$ fragments.

\section{Caste specificity of DG and PPG secretions}

Both queen and worker DG contained large quantities of hydrocarbons and small amounts of tetradecanal and hexadecanal. The latter aldehydes were relatively more abundant in workers than in queens (Fig. 4, Table 1). Hydrocarbons constituted a complex mixture of linear and methyl-branched alkanes, alkenes, and alkadienes containing between 13 and 20 carbons. The PCA conducted on 17 major hydrocarbon peaks from the DG gave ev's higher than 1 for the first five components, which explained $81 \%$ of the total variance (these components explained 32.48, $24.16,12.33,6.99$, and $5.64 \%$ of the total variance, respectively). Projections of the individuals on the first
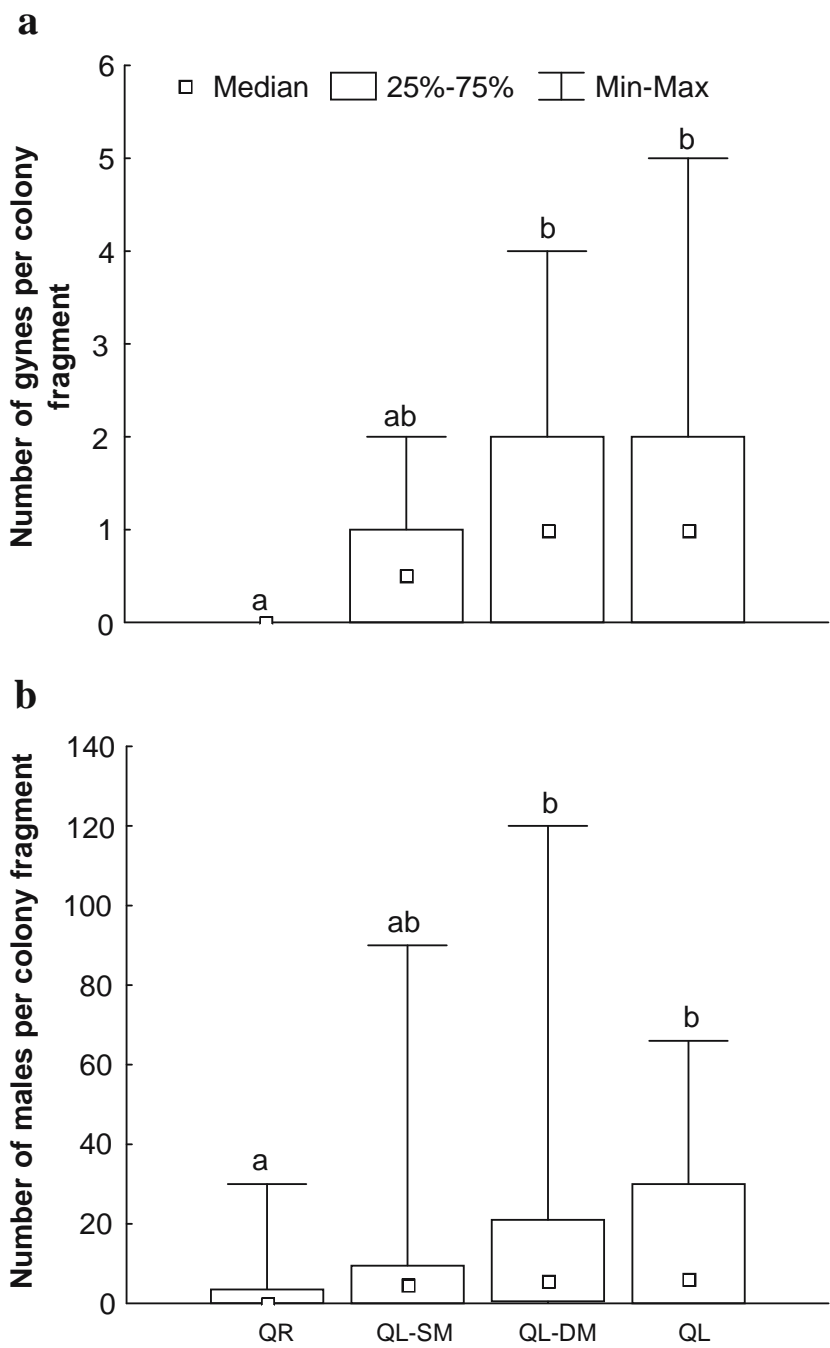

Fig. 3 Number (medians, quartiles and ranges) of gynes (a) and males (b) produced in the A. senilis QR and the various QL fragments after 14 weeks. Different letters denote significant differences $(\mathrm{P}<0.05)$ 
Fig. 4 Secretions of A. senilis worker DG. Compound names are given in Table 2 (peak A is anabasine contamination from the poison sac)

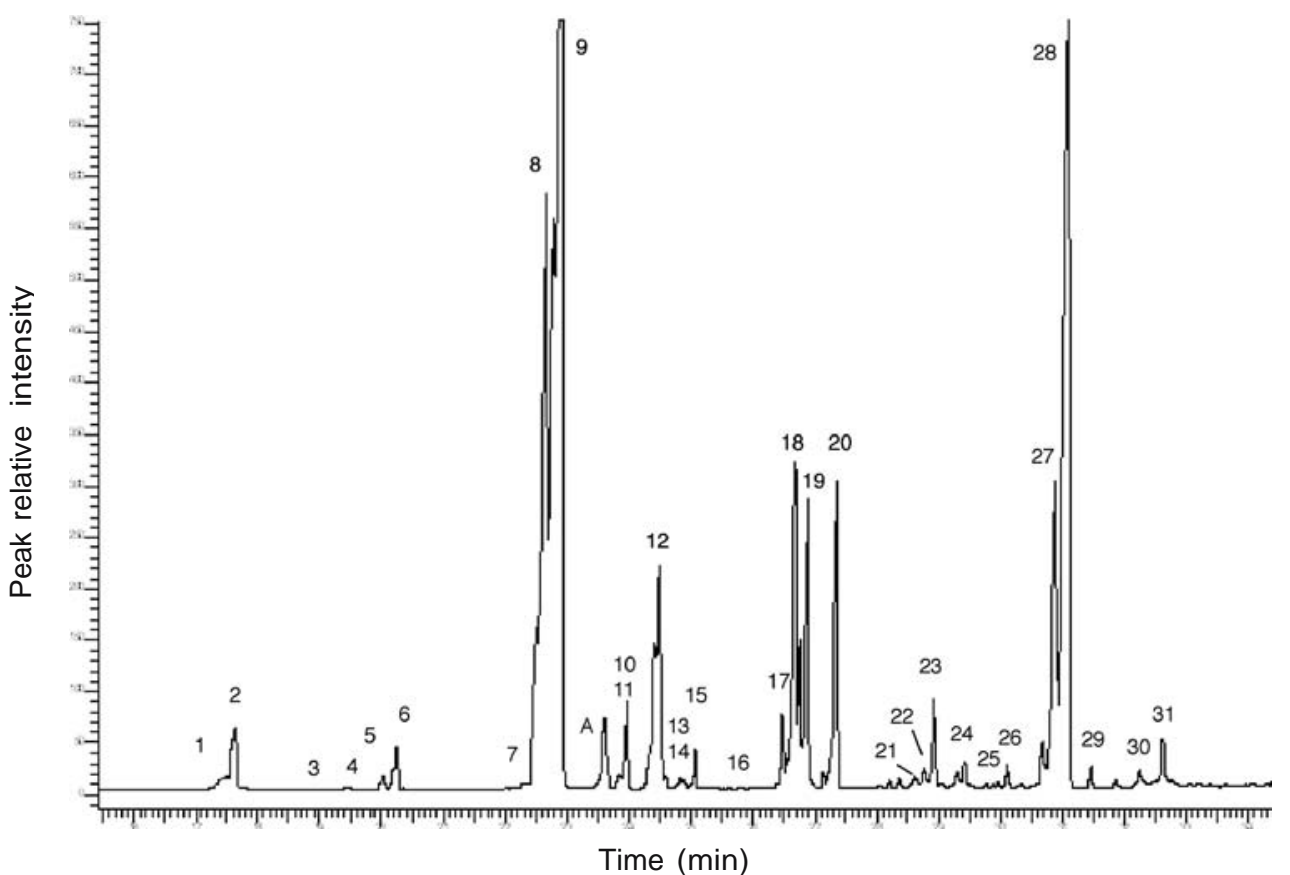

Time (min) two components clearly separated both castes (Fig. 5a). This was mostly due to queens containing relatively more 5- and 3-methylpentadecane, hexadecane, heptadecane, nonadecane, and nonadecene (all positive ev) and less pentadecene, heptadecene, and nonadecadiene (all negative ev). Multiple analysis of variance conducted on the first five components revealed both significant between-caste and between-colony differences (Pillai's trace, $\mathrm{P}<0.001$ and $\mathrm{P}<$ 0.002, respectively). Univariate ANOVA revealed significant between-caste differences on components $1\left(\mathrm{~F}_{1},{ }_{48}=17.76\right.$, $\mathrm{P}<0.001), 2\left(\mathrm{~F}_{1,48}=119.71, \mathrm{P}<0.001\right)$, and $3\left(\mathrm{~F}_{1,48}=6.95\right.$, $\mathrm{P}=0.014)$ and between-colony difference on component 3 $\left(\mathrm{F}_{11,25}=4.25, \mathrm{P}=0.001\right)$. This suggests that caste specificity is very pronounced and may obscure colony specificity.

Worker PPG content has already been described elsewhere (Lenoir et al. 2001). It is copiously filled with longchain linear and methyl-branched alkanes with a carbon length ranging between 25 and 31. Queen PPG contained the same compounds as workers albeit in different proportions (Table 2). PCA of the relative quantities of the 22 major PPG peaks revealed that workers and queens differed in components 1 and 3, which explained 27.15 and $13.10 \%$ of the total variance, respectively (Fig. 5b). Individual profile projection on component 2, which explained $15.87 \%$ of the variance, did not reveal any clear-cut separation between castes or colonies. Components 4-7, which also had ev's higher than 1, explained $11.53,8.79,6.16$, and $4.78 \%$ of the total variance, respectively. Queens were characterized by relatively high proportions of 3-methylheptacosane, 3,7-+3,9-dimethylheptacosane, 4,8-+4,10-dimethyloctacosane, 5-methylnonacosane, triacontane, and 10-+12-methyltriacontane. As in DG, multivariate ANOVA conducted on the first five components confirmed significant differences between castes and colonies (Pillai's trace: $\mathrm{P}<0.001$ and $\mathrm{P}<0.002$, respectively). Castes differed significantly with respect to the first and third components (ANOVA, $\mathrm{F}_{1,58}=254.09, \mathrm{P}<0.001$ and $\mathrm{F}_{1,58}=$ 143.78, $\mathrm{P}<0.001$, respectively) while colonies differed with respect to the first five components (ANOVA, $\mathrm{F}_{1,58}=18.96$, $\mathrm{P}<0.001 ; \mathrm{F}_{1,}{ }_{58}=4.53, \mathrm{P}<0.001 ; \mathrm{F}_{1,}{ }_{58}=13.50, \mathrm{P}<0.001 ;$ $\left.\mathrm{F}_{1,58}=8.44, \mathrm{P}<0.001 ; \mathrm{F}_{1,58}=9.64, \mathrm{P}<0.001\right)$.

\section{Discussion}

Colony fission permits the formation of propagules composed of a queen accompanied by an already efficient worker force. The small number of gynes produced in A. senilis nests is consistent with the hypothesis that in cases of colony fission, excess gyne production is disadvantageous because only one will eventually head each propagule, and that the number of gynes is limited by the size of the mother colony (Bulmer 1983; Bourke and Franks 1995). Males, on the other hand, are the dispersing sex, and therefore their mass production is beneficial. In the field, 172 A. senilis males were produced for each gyne, in accordance with the theory. This is in contrast to A. rudis, in which male production was only fivefold greater than that of gynes, again as predicted from this species' mode of reproduction. Another difference between the two species is that in nature, the A. senilis queen seems to inhibit sexual production, at least in most of the range of colony size, while in A. rudis, gynes are produced only in QR colonies, and males are produced both in QL and QR colonies. 
Table 1 Relative concentration (means \pm SE) of the main compounds identified in the DG of A. senilis workers $(\mathrm{N}=37)$ and queens $(\mathrm{N}=12)$

\begin{tabular}{|c|c|c|c|}
\hline Peak number & Compound names & Queens & Workers \\
\hline 1 & C13: 1 & $0.06 \pm 0.07$ & $0.75 \pm 0.58$ \\
\hline 3 & $5 \mathrm{MeC} 13$ & $0.04 \pm 0.04$ & $0.30 \pm 0.22$ \\
\hline 4 & 3MeC13 & $0.99 \pm 0.61$ & $0.30 \pm 0.20$ \\
\hline 5 & C14: 1 & $0.07 \pm 0.04$ & $0.65 \pm 0.23$ \\
\hline 6 & C14 & $1.46 \pm 0.70$ & $2.71 \pm 1.66$ \\
\hline 7 & C15: 2 & $0.37 \pm 0.40$ & $0.33 \pm 0.15$ \\
\hline 8 & C15: 1 & $1.15 \pm 0.55$ & $12.83 \pm 5.71$ \\
\hline 9 & C15 & $24.61 \pm 8.08$ & $20.91 \pm 0.89$ \\
\hline 10 & 7MeC15 & $0.09 \pm 0.19$ & $0.61 \pm 0.52$ \\
\hline 11 & 5MeC15 & $2.08 \pm 5.19$ & $1.20 \pm 1.02$ \\
\hline 12 & 3MeC15 & $11.69 \pm 6.38$ & $2.15 \pm 1.49$ \\
\hline 13 & C16: 1 & $8.62 \pm 4.22$ & $1.82 \pm 1.30$ \\
\hline 14 & Tetradecanal & $1.29 \pm 1.22$ & $0.40 \pm 0.26$ \\
\hline 15 & C16 & $2.90 \pm 1.74$ & $1.80 \pm 0.94$ \\
\hline 16 & 4MeC16 & $0.30 \pm 0.38$ & $5.29 \pm 4.36$ \\
\hline 17 & C17: 2+ MeC16 & $0.35 \pm 0.37$ & $2.84 \pm 1.76$ \\
\hline 18 & C17: 2 & $4.54 \pm 2.28$ & $6.11 \pm 3.31$ \\
\hline 19 & C17: 1 & $2.25 \pm 1.11$ & $4.71 \pm 1.96$ \\
\hline 20 & $\mathrm{C} 17$ & $8.91 \pm 1.31$ & $4.36 \pm 1.63$ \\
\hline 21 & $9+7+5 \mathrm{MeC} 17$ & $1.34 \pm 0.72$ & $0.70 \pm 0.72$ \\
\hline 22 & C18: 2 & $0.28 \pm 0.10$ & $0.97 \pm 0.63$ \\
\hline 23 & C18: 1 & $1.03 \pm 0.34$ & $1.07 \pm 0.39$ \\
\hline 24 & C18 & $1.13 \pm 0.72$ & $1.07 \pm 0.52$ \\
\hline 25 & 4MeC18 & $0.34 \pm 0.14$ & $0.39 \pm 0.16$ \\
\hline 26 & Hexadecanal & $0.08 \pm 0.06$ & $1.08 \pm 1.00$ \\
\hline 27 & C19: 2 & $5.53 \pm 2.36$ & $8.95 \pm 4.64$ \\
\hline 28 & C19: 1 & $15.04 \pm 6.60$ & $12.72 \pm 7.65$ \\
\hline 29 & C19 & $1.94 \pm 1.17$ & $0.59 \pm 0.34$ \\
\hline 30 & 9MeC19 & $0.65 \pm 2.12$ & $0.19 \pm 0.13$ \\
\hline 31 & C20 & $0.13 \pm 0.27$ & $0.22 \pm 0.18$ \\
\hline
\end{tabular}

Peaks in italics were used in PCA. See the text for peak selection strategy. Compounds are ordered by retention time. Peak numbers refer to Fig. 4.

Most field-collected A. senilis QL colonies had a brood that in all likelihood had originated from the former queen before her disappearance, and from which, gynes could be raised. This possibility was simulated in the lab by splitting the brood between the different nest fragments and showing that QL workers were able to rear a limited number of gynes, which reinforces some of Ledoux's findings (Ledoux 1976b). We can exclude the possibility of worker thelytoky, which has been suggested as a possible mode of gyne production in QL colonies of A. senilis (Ledoux 1984), because this required a thermal shock to which our lab colonies were not submitted. This suggests that under QR conditions, the queen inhibits diploid brood determination to gynes either directly or by affecting worker care behavior towards these larvae (Wilson 1971; Brian 1973; Vargo and Passera 1991; Wheeler 1994).

Males produced in QL colonies could derive either from eggs laid by the former queen or from worker-laid eggs

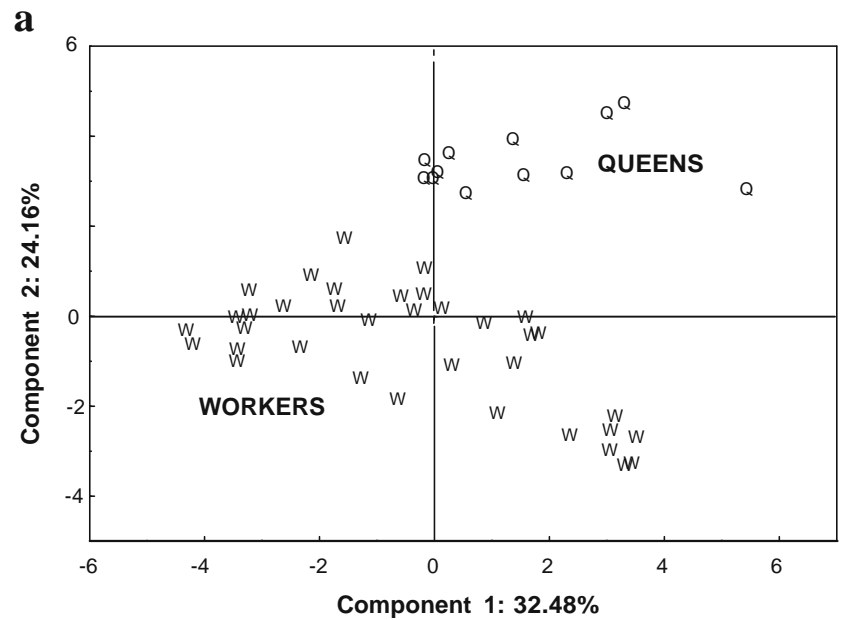

b

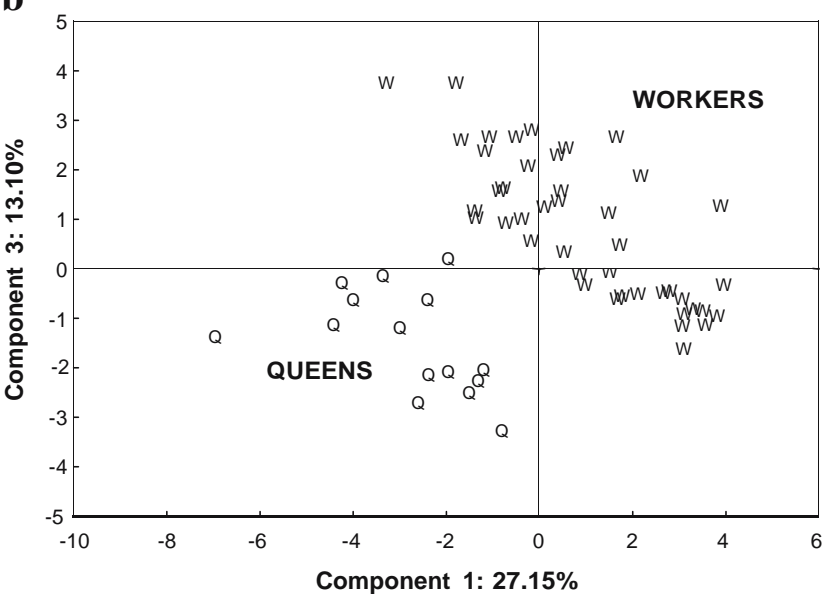

Fig. 5 PCA projections of A. senilis workers (W) and queens (Q) DG (a-components 1 and 2) and PPG (b-components 1 and 3) hydrocarbon profiles. Analyses were done on the 17 and 22 major peaks for DG and PPG, respectively (see Tables 1 and 2)

through arrhenotoky. Moreover, because the percentage of workers having at least one developed oocyte was evenly high under QL and QR conditions, it is unlikely that policing induces workers to refrain from laying eggs in the presence of the queen like in A. cockerelli (Hölldobler and Carlin 1989) and A. smythiesi (Iwanishi et al. 2003). Therefore, under QR conditions, the huge amount of worker-derived haploid eggs might be selectively destroyed and recycled to feed worker larvae, whereas under QL conditions, some of them would be allowed to develop.

The inhibition of sexual production is apparently mediated by contact cues released by the queen. The separation of a colony fragment from the queen through a double mesh, which prevented the transfer of contact cues but allowed volatiles circulation, was sufficient to launch sexual production. By contrast, using a rather conservative statistical test, the augmentation of sexual production by single mesh separation was not significant. In the congeneric species A. smythiesi japonica, queen cues that inhibit male production are also transmitted by contact (Iwanishi and Ohkawara 2005), 
Table 2 Relative concentration (means \pm SE) of the main compounds i dentified in the PPG of A. senilis workers $(\mathrm{N}=37)$ and queens $(\mathrm{N}=12)$

\begin{tabular}{lll} 
Compound names & Queens & Workers \\
\hline C25 & $0.38 \pm 0.08$ & $1.40 \pm 0.21$ \\
11+13MeC25 & $0.87 \pm 0.24$ & $2.57 \pm 0.55$ \\
7MeC25 & $0.44 \pm 0.06$ & $0.88 \pm 0.09$ \\
7,9DMC25 & $1.07 \pm 0.18$ & $1.78 \pm 0.39$ \\
3MeC25 & $1.18 \pm 0.23$ & $1.15 \pm 0.10$ \\
5,9DMeC25 & $0.21 \pm 0.03$ & $0.43 \pm 0.07$ \\
C26 & $2.24 \pm 0.34$ & $0.63 \pm 0.06$ \\
10+12MeC26 & $1.59 \pm 0.20$ & $3.72 \pm 0.29$ \\
8,12DMC26 & $2.24 \pm 0.32$ & $2.82 \pm 0.21$ \\
6,12+6,10DMC26 & $2.18 \pm 0.24$ & $3.34 \pm 0.24$ \\
4,8DMC26 & $1.62 \pm 0.29$ & $3.11 \pm 0.42$ \\
C27 & $2.27 \pm 0.47$ & $4.75 \pm 0.62$ \\
9+11+ 13MeC27 & $7.46 \pm 0.84$ & $15.84 \pm 1.08$ \\
3MeC27 & $13.19 \pm 1.06$ & $8.45 \pm 0.47$ \\
5,9DMC27 & $1.34 \pm 0.08$ & $1.19 \pm 0.21$ \\
3,7+3,9DMC27 & $12.04 \pm 0.85$ & $5.44 \pm 0.70$ \\
10+12MeC28 & $10.65 \pm 0.79$ & $15.66 \pm 0.81$ \\
4MeC28+8,12+ 10,12DMC28 & $11.05 \pm 0.88$ & $11.22 \pm 0.77$ \\
4,8+4,10DMC28 & $4.34 \pm 0.39$ & $2.65 \pm 0.30$ \\
4,8,12TMC28 & $0.96 \pm 0.17$ & $1.71 \pm 0.25$ \\
11MeC29 & $4.56 \pm 0.38$ & $5.67 \pm 0.25$ \\
5MeC29 & $3.73 \pm 0.52$ & $1.25 \pm 0.10$ \\
7,11DMC29 & $0.83 \pm 0.09$ & $0.96 \pm 0.05$ \\
C30 & $3.77 \pm 0.98$ & $1.29 \pm 0.11$ \\
10+ 12MeC30 & $8.23 \pm 0.43$ & $0.88 \pm 0.10$ \\
DMC30 & $1.55 \pm 0.08$ & $1.21 \pm 0.09$ \\
\hline
\end{tabular}

Peaks in italics were used in PCA. See the text for peak selection strategy. Compounds are ordered by retention time.

although in this species, the queen was not reported to inhibit gyne production. The transmission of such contact cues by messenger workers is very likely and would explain why limited antennal contacts through a single mesh did not completely suppress sexual production. However, we cannot exclude the possibility that egg marking with the queen pheromone signals the workers of the queen's presence. At the onset of our experiment, each fragment received the same amount of brood, including queen-laid eggs that were most likely to hatch within 2 weeks. Because sexuals mostly appeared from the fifth week on, this lag in sexual occurrence may be due to the putative egg-marking pheromone that persisted in the colony until all the eggs had hatched. The use of queen eggs as a medium to prevent workers from producing males was demonstrated in C. floridanus (Endler et al. 2004). By contrast, adding queen eggs daily to $\mathrm{L}$. humile QL fragments did not inhibit gyne production, which suggests that eggs do not transmit the queen pheromone in this species (Vargo and Passera 1991).

The origin of queen pheromones inhibiting the production of sexuals is poorly known in ants. Some authors have suggested that these complex signals are emitted by several glands (Vargo and Hulsey 2000). In this study, we have shown that the secretion of two prominent exocrine glands, the DG and the PPG, possess caste-specific compositions, which makes them potential candidates for the production of the queen pheromone. Careful analysis of the variations in compositions of A. senilis PPG shows that different subsets of hydrocarbons reflect caste and, although to a lower extend, colony specificity, raising the possibility that these subsets act independently for caste communication and nestmate recognition, respectively. The lack of trophallaxis in A. senilis reduces the circulation of hydrocarbons between nestmates (Lenoir et al. 2001), which may allow the queen to maintain her own identity within the colony.

The analysis of the DG also indicated important quantitative differences between castes but limited differences between colonies. To the best of our knowledge, this constitutes the first identification of DG constituents in a species of the genus Aphaenogaster. As in many other ant species, it is mostly composed of hydrocarbons but also has small quantities of aldehydes. Queens contain high amounts of pentadecane, 3-methylpentadecane, hexadecane, heptadecane, and nonadecadiene that were only found in small quantities in workers. The role of this gland in caste communication has not yet been studied in detail in ants (but see Dietemann et al. 2003). In the honeybee, queen DG secretion may be part of a complex pheromonal bouquet that signals her fertility as well as regulates the production of queen-like secretion in workers (Dor et al. 2005; KatzavGozansky et al. 2006). Further studies are now needed to determine whether the compounds that dominate A. senilis queen PPG and DG secretions are part of the queen signal.

The intensive nest survey revealed that a few QR colonies with an unusually large number of workers contained gynes. We can thus refute the hypothesis that gyne production is solely limited by resource availability, which may covary with colony size, because queens are only threefold heavier than workers; hence, the production of one or two gynes requires only a small amount of energy (unpublished data). Moreover, if sexual production were completely dependent on colony size, we would not expect it to occur also in small- to medium-sized QL colonies, which it did. It is more probable that when an A. senilis QR colony reaches a very large size, the queen pheromone dilutes within the nest, which allows sexual production. It is also possible that the queen stops producing the pheromone when the colony is large, although this hypothesis, which implies she obtains information on colony size, is less likely. Irrespective of the mechanism, the production of a future queen and many males would be followed by colony fission, as in the army ant and the honeybee swarm (Gotwald 1995; Seeley 1995). This phenomenon could be selected at the colony level because it avoids jeopardizing small colony survival by a large reproductive allocation (which includes the departure of an important worker 
force). However, the high proportion of gynes produced in QL nests lends credence to the existence of an alternative mode of reproduction by which gynes are produced after fission as was initially suggested by Ledoux (1971).

It thus appears that in A. senilis, there is a dual mode of colony fission: One may be queen controlled, whereas the other is worker controlled. In the "swarm-type" mode of colony-fission, queens seem to be successful in delaying sexual production by releasing more inhibiting pheromone than is optimal for workers. As a countermeasure, workers could split during colony migration before the mother colony reaches the queen optimum size, to build an independent QL nest in which sexuals can be reared (QL-fission mode). The hypothetical occurrence of two such reproductive strategies may be possible in a species like A. senilis that performs colony fission and in which worker fitness does not depend exclusively on the queen. Moreover, changing ecological constraints like the availability of nesting sites may prevent natural selection from eliminating one strategy in favor of the other. By contrast, there is no evidence for such workerqueen conflict in A. rudis, which may reflect Bourke and Chan's (1999) claims that the evolution of caste conflict for reproductive allocation should not necessarily occur in all types of social organization.

Acknowledgments This work was supported by "Ecodoca" (European Community-Access to Research Infrastructure action of the Improving Human Potential Program at Doñana Biological Station) to AL and AH and "Picasso" no. 09137XM to AL and XC. RB and XC were supported by grant CGL2006-04968/BOS. Jean-Philippe Christides helped in the chemical analyses. Colony collection and demographic data were obtained with the help of Fernando Amor, Angel Barroso, Ana Carvajal, Raymond Jegat, Isabel Luque, Thibaut Monnin, and Javier Retana. We thank Ray Heithaus and David Lubertazzi for valuable information on A. rudis and Saturo Iwanishi for interesting comments on the manuscript. We thank Naomi Paz for editorial assistance.

\section{References}

Alaux C, Jaisson P, Hefetz A (2005) Reproductive decision in semelparous social insects: a pace-maker queen in bumblebees colonies. Behav Ecol Sociobiol 59:270-277

Alaux C, Jaisson P, Hefetz A (2006) Regulation of worker reproduction in bumblebees: workers eavesdrop on a queen signal. Behav Ecol Sociobiol 60:439-446

Aron S, Keller L, Passera L (2001) Role of resource availability on sex, caste and reproductive allocation ratios in the Argentine ant Linepithema humile. J Anim Ecol 70:831-839

Backus VL (1995) Rules for allocation in a temperate forest antdemography, natural selection, and queen-worker conflict. Am Nat 145:775-796

Bourke AFG, Chan GL (1999) Queen-worker conflict over sexual production and colony maintenance in perennial social insects. Am Nat 154:417-426

Bourke AFG, Franks NR (1995) Social evolution in ants. Princeton Univ. Press, Princeton, NJ
Bourke AFG, Ratnieks FLW (1999) Kin conflict over caste determination in social Hymenoptera. Behav Ecol Sociobiol 46:287-297

Brian MV (1973) Caste control through worker attack in the ant Myrmica. Insectes Soc 20:87-102

Brian MV (1979) Habitat differences in sexual production by two coexistent ants Tetramorium caespitum, Lasius alienus, in southern England. J Anim Ecol 48:943-953

Bulmer MG (1983) Sex ratio theory in social insects with swarming. J Theor Biol 100:329-340

Butler CG (1959) The source of the substance produced by a queen honeybee (Apis mellifera) which inhibits development of the ovaries of the workers of its colony. Proc R Entomol Soc Lond 34:137-138

Butler L (1961) The scent of queen honey bees (Apis mellifera) that causes partial inhibition of queen rearing. J Insect Physiol 7:258-264

Cerdá X, Dahbi A, Retana J (2002) Spatial patterns, temporal variability, and the role of multi-nest colonies in a monogynous Spanish desert ant. Ecol Entomol 27:7-15

Craig R (1980) Sex investment ratios in social Hymenoptera. Am Nat 116:311-323

Cuvillier-Hot V, Cobb M, Malosse C, Peeters C (2001) Sex, age and ovarian activity affect cuticular hydrocarbons in Diacamma ceylonense, a queenless ant. J Insect Physiol 47:485-493

Cuvillier-Hot V, Lenoir A, Crewe R, Malosse C, Peeters C (2004) Fertility signaling and reproductive skew in queenless ants. Anim Behav 68:1209-1219

de Menten L, Fournier D, Brent C, Passera L, Vargo EL, Aron S (2005) Dual mechanism of queen influence over sex ratio in the ant Pheidole pallidula. Behav Ecol Sociobiol 58:527-533

Dietemann V, Peeters C, Liebig J, Thivet V, Hölldobler B (2003) Cuticular hydrocarbons mediate discrimination of reproductives and non reproductives in the ant Myrmecia gulosa. Proc Natl Acad Sci USA 100:10341-10346

Dor R, Katzav-Gozansky T, Hefetz A (2005) Dufour's gland pheromone as a reliable fertility signal among honeybee (Apis mellifera) workers. Behav Ecol Sociobiol 58:270-276

Elmes GW, Wardlaw JC (1982) A population study of the ants Myrmica sabuleti and Myrmica scabrinodis living at two sites in the south of England. II. Effect of above-nest vegetation. J Anim Ecol 51:665-680

Endler A, Liebig J, Schmitt T, Parker JE, Jones GR, Schreier P, Hölldobler B (2004) Surface hydrocarbons of queen eggs regulate worker reproduction in a social insect. Proc Natl Acad Sci USA 101:2945-2950

Gotwald WH Jr (1995) Army ants: the biology of social predation. Cornell Univ. Press, Ithaca, NY

Hammond RL, Keller L (2004) Conflict over male parentage in social insects. PLoS Biol 2:1472-1482

Headley AE (1949) A population study of the ant Aphaenogaster fulva ssp. aquia Buckley (Hymenoptera, Formicidae). Ann Entomol Soc Am, 42:265-272

Heinze J, Stengl B, Sledge MF (2002) Worker rank, reproductive status and cuticular hydrocarbon signature in the ant, Pachycondyla cf. inversa. Behav Ecol Sociobiol 52:59-65

Herbers JM, Banschbach VS (1998) Food supply and reproductive allocation in forest ants: repeated experiments give different results. Oikos 83:145-151

Herbers JM, Banschbach VS (1999) Plasticity of social organization in a forest ant species. Behav Ecol Sociobiol 45:451-465

Herbers JM, DeHeer CJ, Foitzik S (2001) Conflict over sex allocation drives conflict over reproduction in perennial social insects. Am Nat 158:178-192

Hölldobler B, Carlin NF (1989) Colony founding, queen control and worker reproduction in the ant Aphaenogaster (=Novomessor) cockerelli (Hymenoptera: Formicidae). Psyche 96:131-151 
Hoover SER, Keeling CI, Winston ML, Slessor KN (2003) The effect of queen pheromones on worker honey bee ovary development. Naturwissenschaften 90:477-480

Iwanishi S, Ohkawara K (2005) The mechanism of the queen signal in regulation of worker reproduction in the myrmicine ant Aphaenogaster smythiesi japonica. Ethol Ecol Evol 17:27-39

Iwanishi S, Hasegawa E, Ohkawara K (2003) Worker oviposition and policing behaviour in the myrmicine ant Aphaenogaster smythiesi japonica Forel. Anim Behav 66:513-519

Julian GE, Fewell JH, Gadau J, Johnson RA, Larrabee D (2002) Genetic determination of the queen caste in an ant hybrid zone. Proc Natl Acad Sci USA 99:8157-8160

Katzav-Gozansky T, Boulay R, Soroker V, Hefetz A (2004) Queensignal modulation of worker pheromonal composition in honeybees. Proc R Soc Lond B 271:2065-2069

Katzav-Gozansky T, Boulay R, Soroker V, Hefetz A (2006) Queen pheromones affecting the production of queen-like secretion in workers. J Comp Physiol A 192:737-742

Keller L, Nonacs P (1993) The role of queen pheromones in social insects: queen control or queen signal? Anim Behav 45:787-794

Lahav S, Soroker V, Hefetz A, Vander Meer RK (1999) Direct behavioral evidence for hydrocarbons as ant recognition discriminators. Naturwissenschaften 86:246-249

Ledoux A (1971) Un nouveau mode de bouturage de société chez la fourmi Aphaenogaster senilis Mayr. C R Acad Sci Ser D Sci Nat 273:83-85

Ledoux A (1976a) Bouturage expérimental de colonie chez la fourmi Aphaenogaster senilis Mayr. C R Acad Sci Ser D Sci Nat 283:1061-1063

Ledoux A (1976b) Inhibition exercée sur l'apparition de nouvelles femelles ailées, par le femelle reine pondeuse chez Aphaenogaster senilis (Hyméoptère Formicoidea). C R Acad Sci Ser D Sci Nat 283:1197-200

Ledoux A (1984) Sur la présence d'ouvrières à parthénogenèse thélytoque observée chez Aphaenogaster senilis (Mayr.) (Hyménoptère Formicoidea). C R Acad Sci Ser III Sci Vie 299:859-861

Lenoir A, Fresneau D, Errard C, Hefetz A (1999) Individuality and colonial identity in ants. In: Detrain C, Deneubourg JL, Pasteels J (eds) Information processing in social insects. Birkhauser, Basel, pp 219-237

Lenoir A, Hefetz A, Simon T, Soroker V (2001) Comparative dynamics of gestalt odour formation in two ant species Camponotus fellah and Aphaenogaster senilis (Hymenoptera: Formicidae). Physiol Entomol 26:275-283

Liebig J, Peeters C, Oldham NJ, Markstadter C, Hölldobler B (2000) Are variations in cuticular hydrocarbons of queens and workers a reliable signal of fertility in the ant Harpegnathos saltator? Proc Natl Acad Sci USA 97:4124-4131

Lim SP, Lee CY (2005) Effects of queen body parts on the production of new sexuals in the Pharaoh's ant, Monomorium pharaonis (Hymenoptera: Formicidae). Sociobiology 46:677-688

Littell RC, Milliken GA, Stroup WW, Wolfinger RD (1996) SAS system for mixed models. SAS Institute, Cary

Mehdiabadi N, Reeve HK, Mueller UG (2003) Queens versus workers: sex-ratio conflicts in eusocial insects. Trends Ecol Evol 18:88-93

Monnin T, Ratnieks FL, Jones GR, Beard R (2002) Pretender punishment induced by chemical signaling in a queenless ant. Nature 419:61-65

Oster G, Wilson EO (1978) Caste and ecology in the social insects. Princeton Univ. Press, Princeton, NJ

Pamilo P (1991) Evolution of colony characteristics in social insects. I. Sex allocation. Am Nat 137:83-107

Pearcy M, Aron S (2006) Local resource competition and sex ratio in the ant Cataglyphis cursor. Behav Ecol:569-574
Peeters C, Monnin T, Malosse C (1999) Cuticular hydrocarbons correlated with reproductive status in a queenless ant. Proc R Soc Lond B 266:1323-1327

Pettis JS, Winston ML, Collins AM (1995) Suppression of queen rearing in European and Africanized honey bees Apis mellifera L. by synthetic queen mandibular pheromone. Insectes Soc 42:113121

Quinn GP, Keough MJ (2002) Experimental design and data analysis for biologists. Cambridge Univ. Press, Cambridge

Ratnieks FLW (1988) Reproductive harmony via mutual policing by workers in eusocial Hymenoptera. Am Nat 132:217-236

Seeley TD (1995) The wisdom of the hive: the social physiology of honey bee colonies. Harvard Univ. Press, London

Sundström L (1995) Sex allocation and colony maintenance in monogyne and polygyne colonies of Formica truncorum (Hymenoptera: Formicidae): the impact of kinship and mating structure. Am Nat 146:182-201

Talbot M (1951) Populations and hibernating conditions of the ant Aphaenogaster (Attomyrma) rudis Emery (Hymenoptera: Formicidae). Ann Entomol Soc Am 44:302-307

Thomas ML, Parry LJ, Allan RA, Elgar MA (1999) Geographic affinity, cuticular hydrocarbons and colony recognition in the Australian meat ant Iridomyrmex purpureus. Naturwissenschaften 86:87-92

Vander Meer RK, Glancey BM, Lofgren CS, Glover A, Tumlinson JH, Rocca J (1980) The poison sac of red imported fire ant queens: source of a pheromone attractant. Ann Entomol Soc Am 73:609-612

Vander Meer RK, Morel L (1998) Nestmate recognition in ants. In: Vander Meer RK, Breed M, Winston M, Espelie KE (eds) Pheromone communication in social insects. Westview, Boulder, CO, pp 79-103

Vargo EL (1988) A bioassay for a primer pheromone of queen fire ants (Solenopsis invicta) which inhibits the production of sexuals. Insectes Soc 35:382-392

Vargo EL (1997) Poison gland of queen fire ants (Solenopsis invicta) is the source of a primer pheromone. Naturwissenschaften 84:507-510

Vargo EL, Hulsey CD (2000) Multiple glandular origins of queen pheromones in the fire ant Solenopsis invicta. J Insect Physiol 46:1151-1159

Vargo EL, Passera L (1991) Pheromonal and behavioral queen control over the production of gynes in the Argentine ant Iridomyrmex humilis (Mayr). Behav Ecol Sociobiol 28:161-169

Vargo EL, Passera L (1992) Gyne development in the Argentine ant Iridomyrmex humilis role of overwintering and queen control. Physiol Entomol 17:193-201

Volny VP, Gordon DM (2002) Genetic basis for queen-worker dimorphism in a social insect. Proc Natl Acad Sci USA 99:6108-6111

Wagner D, Tissot M, Cuevas W, Gordon DM (2000) Harvester ants utilize cuticular hydrocarbons in nestmate recognition. J Chem Ecol 26:2245-2257

Walin L, Seppä P (2001) Resource allocation in the red ant Myrmica ruginodis-an interplay of genetics and ecology. J Evol Biol 14:694-707

Wheeler DE (1994) Nourishment in ants: patterns in individuals and societies. In: Hunt JH, Nalepa CA (eds) Nourishment and evolution in insect societies. Westview, Boulder, CO, pp 245-278

Wilson EO (1971) The insect societies. Harvard Univ. Press, Cambridge.

Winston M, Higo HA, Slessor KN (1990) Effects of various dosages of queens mandibular gland pheromone on the inhibition of queen rearing in the honey bee (Hymenoptera: Apidae). Ann Entomol Soc Am 83:234-238

Woyciechowski M, Łomnicki A (1987) Multiple mating of queens and the sterility of workers among eusocial Hymenoptera. J Theor Biol 128:317-327

Zar JH (1984) Biostatistical analyses. Princeton Hall, London 